\title{
Assessment of the McCollough effect by a shift in psychometric function
}

\author{
LORRAINE G. ALLAN, SHEPARD SIEGEL, and PAMELA TOPPAN \\ McMaster University, Hamilton, Ontario, Canada \\ and \\ GREGORY R. LOCKHEAD \\ Duke University, Durham, North Carolina
}

\begin{abstract}
Following adaptation to chromatic grids, we assessed the orientation-contingent color aftereffect with a new procedure-a shift in the psychometric function from the preadaptation level. With this procedure, the conditions that did and did not induce the aftereffect were the same as those previously reported with other measurement procedures. The psychometric function shift provides a new, simple, and objective technique for evaluation of illusory color.
\end{abstract}

In 1965, McCollough reported a color aftereffect contingent on line orientation. Since then, McCollough's (1965) observation has been amply confirmed (see reviews by Harris, 1980; Stromeyer, 1978), and other contingent color aftereffects have been demonstrated-for example, color contingent on movement direction (Hepler, 1968; Mayhew \& Anstis, 1972; Stromeyer \& Mansfield, 1970), spatial frequency (Breitmeyer \& Cooper, 1972; Leppmann, 1973; Lovegrove \& Over, 1972), and dot size (MacKay \& MacKay, 1975).

Contingent color aftereffects have been assessed with a variety of different procedures. In the early demonstrations, subjects were simply asked to describe the color of the test stimulus (e.g., Breitmeyer \& Cooper, 1972; Hepler, 1968; McCollough, 1965). Later studies incorporated techniques that allowed more quantitative and objective assessments of the size of the aftereffect: forcedchoice color naming (e.g., Broerse \& Crassini, 1984; Harris \& Gibson, 1968), magnitude estimation (e.g., Broerse \& Crassini, 1984; Stromeyer, 1969), color matching (e.g., Houck \& Hoffman, 1986; Stromeyer, 1969), and color cancellation (e.g., Riggs, White, \& Eimas, 1974; Siegel \& Allan, 1985, 1987).

Recently, Allan, Siegel, Collins, and MacQueen (1989) have described a new color aftereffect: illusory color seen on achromatic words following exposure to these words in color. They used a variant of the method of constant stimuli to assess the presence of the color aftereffect. Psychometric functions were determined both before and after adaptation. The magnitude of the aftereffect was in-

This research was supported by grants to L. G. Allan and S. Siegel from the Natural Sciences and Engineering Research Council of Canada and from the National Institutes of Mental Health. Appreciation is expressed to Caroline King for running some of the subjects. Correspondence concerning this article should be addressed to either Lorraine $\mathbf{G}$. Allan or Shepard Siegel, Department of Psychology, McMaster University, Hamilton, Ontario L8S 4K1, Canada. dexed by the shift in the psychometric function from preadaptation to postadaptation. Allan et al. (1989) interpreted the shift in the psychometric function to indicate that chromatic adaptation to words produces illusory colors. Thus, for Allan et al. (1989), the shift in the psychometric function was perceptually based rather than attributable to a response bias.

As with other illusory phenomena, it is important to establish that the shift in responding from preadaptation to postadaptation does reflect a perceptual change rather than a change in response bias. In the present experiment, we used the method described by Allan et al. (1989) to measure the presence of an orientation-contingent color aftereffect.

We evaluated the orientation-contingent color aftereffect, as assessed by the shift in the psychometric function, under various conditions. If response bias contributes to psychometric function shifts, we would expect to see such shifts in situations that, although involving presentation of chromatic orientation stimuli, do not favor the development of color aftereffects. Such circumstances prevail when the aftereffect is assessed with an eye that was occluded during adaptation (see, e.g., Kaufman, May, \& Kunen, 1981; McCollough, 1965; Meyer, Coleman, Dwyer, \& Lehman, 1982; Murch, 1972; White \& Riggs, 1974), or when the orientation and chromatic components of the adaptation stimuli do not differ in luminance (Ellis, 1977; Mikaelian, 1980).

McCollough (1965) noted that when only one eye was exposed during adaptation, no evidence of an aftereffect was seen when the other (unadapted) eye was tested. Others (e.g., Kaufman, May, \& Kunen, 1981; Meyer, Coleman, Dwyer, \& Lehman, 1982; Murch, 1972; White \& Riggs, 1974) have confirmed that, with complete occlusion of the unadapted eye, there is little, if any, interocular transfer of pattern-contingent color aftereffects. In the present experiment, the shift in the psychometric function was used to measure interocular transfer of the 
McCollough effect. In one condition (interocular), one eye was adapted, and the nonadapted eye was tested for the aftereffect. In a second condition (monocular), one eye was adapted and the adapted eye was tested. In a third condition (binocular), both eyes were adapted and tested. On the basis of previous studies, we would expect the shift in psychometric function, from preadaptation to postadaptation, to be less in the interocular condition than in either the monocular or the binocular condition. If, however, the shift in the function reflects a response bias, we would expect the interocular condition, which does not favor aftereffect development, nevertheless to induce such a shift.

Several investigators have reported that luminance contrast influences the size of the orientation-contingent color aftereffect. Ellis (1977) changed luminance contrast by varying the luminance of the achromatic bars, and found that the size of the aftereffect decreased as luminance contrast decreased. Mikaelian (1980) varied the luminance of both the achromatic and the chromatic bars. He also reported that the size of the McCollough effect decreased as the luminance contrast was decreased, and that this was the case both when the luminance of achromatic bars was higher than the luminance of chromatic bars and when it was lower. When the chromatic bars and the achromatic bars were isoluminant, the McCollough effect was very weak, in comparison with the size for the largest luminance contrast used. In the fourth condition in the present experiment (isoluminant), we decreased the luminance contrast. As in the binocular condition, both eyes were adapted and tested. If the shift in function results from response bias, we would expect such a shift in the isoluminant condition.

METHOD
Subjects
The subjects were 29 male and female students with no previous ex-
perience in contingent aftereffect tasks. They were not screened for color
deficiencies. They were enrolled in introductory psychology at McMaster
University and received course credit for their participation.
Design
There were four groups: binocular $(n=7)$, monocular $(n=7)$, in-
terocular $(n=7)$, and isoluminant $(n=8)$.
Each session consisted of three phases: preadaptation assessment (about
10 min), adaptation ( 25 min), and postadaptation assessment (about
10 min). The room was darkened during adaptation and assessments.
There was a 2-min period in normal room illumination after adaptation
prior to the postadaptation assessment.

\section{Apparatus and Materials}

The grids were presented on a Zenith monitor (Model 1490) with a VGA display card. Temporal parameters, stimulus presentation, and recording of responses were controlled by a Tandy 3000 computer.

The monitor was located about $125 \mathrm{~cm}$ from the subject. The color on the monitor is determined by the combination of relative red $(R)$, green $(G)$, and blue (B) input. When each input is at its maximum value $(R=G=B=63)$, the result is white. When each input is at its minimum value $(R=G=B=0)$, the result is black. Changing the relative proportions of $R, G$, and $B$ produces various hues at different saturations. Chromaticity and illuminance was assessed with a Minolta Chroma Meter II Incident. Measurements were taken with the display completely illuminated with the color being assessed, using a procedure similar to that in Houck and Hoffman (1986). RGB values, illuminance values (lux),
Table 1

RGB Values, Illuminance Values (Lux), and Chromaticity Values (CIE $x$ - and $y$-Coordinates)

\begin{tabular}{lrrrrrr}
\hline Color & R & G & B & Illuminance & $x$ & $y$ \\
\hline \multicolumn{7}{c}{ Achromatic Bars } \\
black & 0 & 0 & 0 & & & \\
gray & 34 & 34 & 34 & 12.7 & .304 & .342 \\
\multicolumn{7}{c}{ Adaptation } \\
magenta & 63 & 0 & 25 & 13.1 & .552 & .311 \\
green & 0 & 63 & 0 & 48.9 & .309 & .601 \\
\multicolumn{7}{c}{ Adinocular, Monocular, Interocular) } \\
magenta & 63 & 0 & 25 & 13.1 & .552 & .311 \\
green & 0 & 38 & 0 & 12.7 & .312 & .602 \\
\multicolumn{7}{c}{ Assessments } \\
M2 & 63 & 59 & 63 & 57.0 & .297 & .315 \\
M1 & 63 & 61 & 63 & 59.3 & .297 & .324 \\
Achromatic & 63 & 63 & 63 & 62.0 & .298 & .334 \\
G1 & 61 & 63 & 61 & 62.6 & .299 & .342 \\
G2 & 59 & 63 & 59 & 63.0 & .299 & .351 \\
\hline
\end{tabular}

and chromaticity values (CIE $x$ - and $y$-coordinates) are reported in Table 1.

The grid was $90.0 \times 94.1 \mathrm{~mm}$ (width $\times$ height), subtending $4.12^{\circ}$ and $4.31^{\circ}$ of visual angle, respectively. The grid was presented on a black background in the middle of the monitor screen. It was composed of 24 bars, either horizontal or vertical. A horizontal bar subtended $18^{\circ}$ of visual angle and a vertical bar subtended $17^{\circ}$ of visual angle. For the binocular, monocular, and interocular conditions, alternate bars were black; for the isoluminant condition, these bars were gray. In the isoluminant adaptation condition, the achromatic and chromatic bars were nearly isoluminant, and the two grids were essentially isoluminant.

\section{Procedure}

Subjects participated in the experiment individually, with the experimenter present in the room throughout the session. The subjects were instructed to look at the monitor and to keep their heads upright at all times.

During adaptation, a grid consisting of achromatic and green horizontal bars alternated every $3 \mathrm{sec}$ with a grid consisting of achromatic and magenta vertical bars.

For both preadaptation and postadaptation assessments, the subjects received 50 presentations of each grid orientation. On each presentation, the background could be one of five colors: one of two shades of pale magenta ( $M 1$ and $M 2$, with $M 2$ being more saturated than $M 1$ ), one of two shades of pale green ( $G 1$ and $G 2$, with $G 2$ being more saturated than $\mathrm{G} 1$ ), or achromatic. Grid orientation (horizontal or vertical) and color (M1, M2, G1, G2, and achromatic) were randomly ordered, with the restriction that each orientation was presented in each color 10 times. The subject had to make a binary response, "green" or "pink," on each assessment trial. The subject indicated this response by pressing one of two keys on the computer keyboard. The grid remained on the screen until the subject responded.

In the interocular condition, the right eye was patched during adaptation and the left eye was patched during preadaptation and postadaptation assessments. In the monocular condition, the right eye was patched in all three phases. In the binocular and isoluminant conditions, there was no patching. In the two conditions involving patching, the patch was removed during the 2 -min period in normal room illumination before the postadaptation assessment.

\section{RESULTS AND DISCUSSION}

The psychometric function relating the probability of the subject's reporting that the grid appeared green, $P(G)$, 

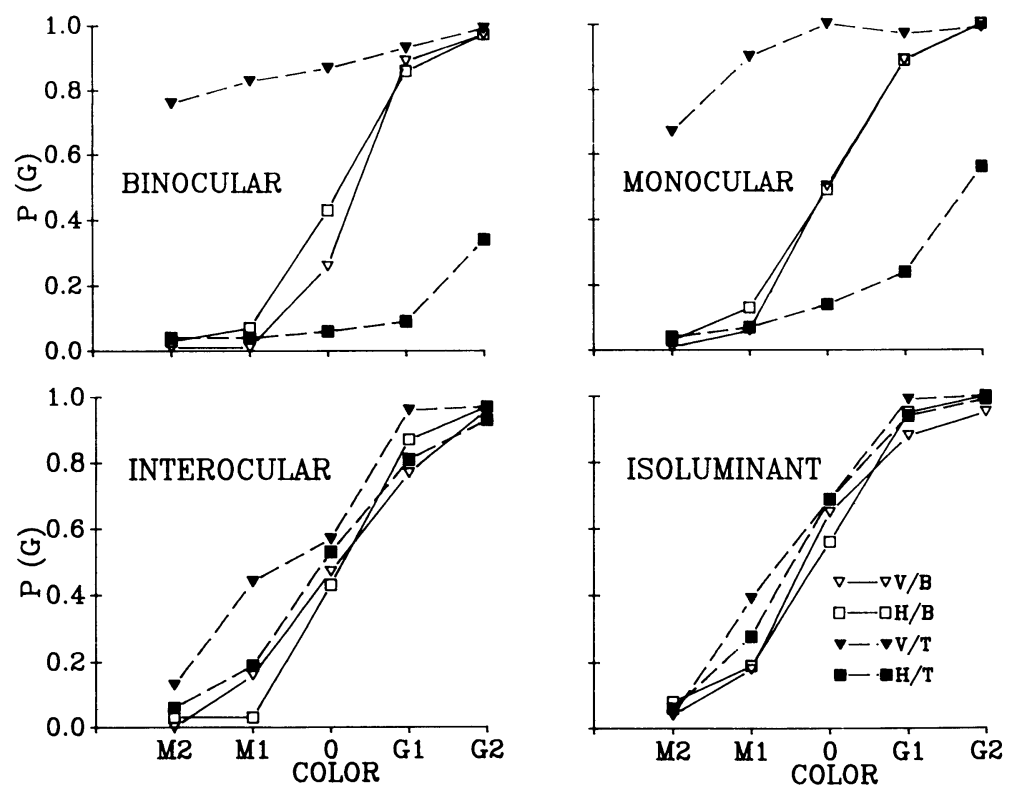

Figure 1. Baseline (unfilled symbols) and test (filled symbols) psychometric functions for the four conditions: binocular (left) and monocular (right) on the top, interocular (left) and isoluminant (right) on the bottom. Inverted triangles are for the vertical grid and rectangles are for the horizontal grid. $\mathrm{M} 2$ and $\mathrm{M1}$ are two shades of magenta, G2 and G1 are two shades of green, and 0 is achromatic.

to the physical characteristics of the assessment stimulus (ranging from M2 to G2) was determined. The functions are shown in Figure 1, separately for each condition.

The preadaptation functions span the full range from 0 to 1.00 , indicating that subjects were sensitive to the physical differences used. In all conditions, the preadaptation functions for the two orientations were similar. A Wilcoxon test indicated that, in preadaptation, the number of green responses to the vertical grid did not differ significantly from the number to the horizontal grid [ $T=143.5, n=25$ (4 ties), $p>.05$ ].

It is clear from Figure 1 that postadaptation performance in the interocular and isoluminant conditions was different from that in the binocular and monocular conditions. A Kruskal-Wallis $H$ test, performed on the difference between the number of green responses to the two orientations in postadaptation, showed that the conditions differed significantly $(H=20.00, n=29, p<.001)$. Pairwise comparisons, using Ryan's procedure (Mendenhall \& Ramey, 1973), indicated that the difference was greater in the binocular condition than in the interocular condition $(p<.01)$ or in the isoluminant condition $(p<.001)$. The binocular condition did not differ from the monocular condition $(p>.05)$, and the interocular condition did not differ from the isoluminant condition $(p>.05)$.

The results of this experiment are consistent with those observed in experiments in which other measurement procedures have been used. First, there is little, if any, evidence of a color aftereffect in the eye that was occluded during adaptation. Second, the size of the color aftereffect decreases as the luminance contrast between the achromatic and chromatic bars is decreased. The data from the present experiment provide strong evidence that the shift in psychometric function from preadaptation to postadaptation is a manifestation of illusory color rather than response bias. This shift has recently been useful for evaluating color aftereffects induced by presentation of chromatic words (Allan et al., 1989). The results of the present experiment indicate that it is a generally useful technique for objective evaluation of illusory color.

\section{REFERENCES}

Allan, L. G., Siegel, S., Collins, J. C., \& MacQueen, G. M. (1989). Color aftereffect contingent on text. Perception \& Psychophysics, 46, 105-113.

Breitmeyer, B. G., \& CoOPER, L. A. (1972). Frequency-specific color adaptation in the human visual system. Perception \& Psychophysics, 11, 95-96.

Broerse, J., \& Crassini, B. (1984). Investigations of perception and imagery using CAEs: The role of experimental design and psychophysical method. Perception \& Psychophysics, 35, 155-164.

ELLIS, S. R. (1977). Orientation selectivity of the McCollough effect: Analysis by equivalent contrast transformation. Perception \& Psychophysics, 22, 539-544.

HARRIS, C. S. (1980). Insight or out of sight? Two examples of perceptual plasticity in the human adult. In C. S. Harris (Ed.), Visual coding and adaptability (pp. 95-149). Hillsdale, NJ: Erlbaum.

Harris, C. S., \& GiBson, A. R. (1968). Is orientation-specific color adaptation in human vision due to edge-detectors, afterimages or "dipoles'? Science, 162, 1506-1507.

HEPLER, N. (1968). Color: A motion-contingent aftereffect. Science, 162, 376-377.

Houck, M. R., \& Hoffman, J. E. (1986). Conjunction of color and form without attention: Evidence from an orientation-contingent color 
aftereffect. Journal of Experimental Psychology: Human Perception \& Performance, 12, 186-199.

Kaufman, J. A., May, J. G., \& Kunen, S. (1981). Interocular transfer of orientation-contingent color aftereffects with external and internal adaptation. Perception \& Psychophysics, 30, 547-551.

LePPMANN, P. K. (1973). Spatial frequency dependent chromatic aftereffects. Nature, 242, 411-412.

LOVEgrove, W., \& OVER, R. (1972). Color adaptation of spatial frequency detectors in the human visual system. Science, 176, 541-543.

MaCKAY, D. M., \& MaCKay, V. (1975). Dichoptic induction of McCollough-type effects. Quarterly Journal of Experimental Psychology, 27, 225-233.

MAYHEW, J. E. W., \& ANSTis, S. M. (1972). Movement aftereffects contingent on color, intensity, and pattern. Perception \& Psychophysics, 12, 77-85.

McCollough, C. (1965). Color adaptation of edge detectors in the human visual system. Science, 149, 1115-1116.

Mendenhall, W., \& Ramey, M. (1973). Statistics for psychology. North Scituate, MA: Duxbury Press.

Meyer, G. E., Coleman, A., Dwyer, T., \& Lehman, I. (1982). The McCollough effect in children. Child Development, 53, 838-840.

Mikaelian, H. H. (1980). Effective luminance contrast as a parameter in contingent aftereffects. Perception \& Psychophysics, 27, 531-536.

MURCH, G. M. (1972). Binocular relationships in a size and color orien- tation specific aftereffect. Journal of Experimental Psychology, 93, 30-34.

Riggs, L. A., White, K. D., \& Eimas, P. D. (1974). Establishment and decay of orientation-contingent aftereffects of color. Perception \& Psychophysics, 16, 535-542.

Siegel, S., \& Allan, L. G. (1985). Overshadowing and blocking of the orientation-contingent color aftereffect. Learning \& Motivation, 16, 125-138.

Siegel, S., \& Allan, L. G. (1987). Contingency and the McCollough effect. Perception \& Psychophysics, 42, 281-285.

Stromeyer, C. F., [III] (1969). Further studies of the McCollough effect. Perception \& Psychophysics, 6, 105-110.

Stromeyer, C. F., III (1978). Form-color aftereffects in human vision. In R. Held, H. Leibowitz, \& H. L. Teuber (Eds.), Handbook of sensory physiology: Vol. 8. Perception (pp. 97-142). New York: Springer-Verlag.

Stromeyer, C. F., III, \& Mansfield, R. J. W. (1970). Colored aftereffects produced with moving edges. Perception \& Psychophysics, $7,108-114$.

White, K. D., \& RigGs, L. A. (1974). Angle-contingent color aftereffects. Vision Research, 14, 1147-1154.

(Manuscript received May 29, 1990.) 